Afr. J. Trad. CAM (2007) 4 (2): 205 - 210

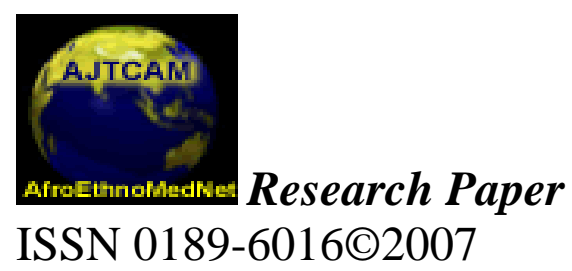

Afr. J. Traditional, Complementary and Alternative Medicines www.africanethnomedicines.net

\title{
IDENTIFYING HEARING LOSS BY MEANS OF IRIDOLOGY
}

\section{Natalie Stearn and De Wet *Swanepoel}

\author{
Department of Communication Pathology, University of Pretoria, South Africa, Pretoria 0002 \\ *E-mail: dewet.swanepoel@up.ac.za, Tel: 2712 4202949, Fax: 27124203517
}

\begin{abstract}
Isolated reports of hearing loss presenting as markings on the iris exist, but to date the effectiveness of iridology to identify hearing loss has not been investigated. This study therefore aimed to determine the efficacy of iridological analysis in the identification of moderate to profound sensorineural hearing loss in adolescents. A controlled trial was conducted with an iridologist, blind to the actual hearing status of participants, analyzing the irises of participants with and without hearing loss. Fifty hearing impaired and fifty normal hearing subjects, between the ages of 15 and 19 years, controlled for gender, participated in the study. An experienced iridologist analyzed the randomised set of participants' irises. A $70 \%$ correct identification of hearing status was obtained by iridological analyses with a false negative rate of $41 \%$ compared to a $19 \%$ false positive rate. The respective sensitivity and specificity rates therefore came to $59 \%$ and $81 \%$. Iridological analysis of hearing status indicated a statistically significant relationship to actual hearing status $(P<0.05)$. Although statistically significant sensitivity and specificity rates for identifying hearing loss by iridology were not comparable to those of traditional audiological screening procedures.
\end{abstract}

Key words: Audiology; Hearing loss, Iridology, Screening

\section{Introduction}

Audiology is the profession dedicated to hearing loss in humans, including its identification, diagnosis, and intervention. One of the major roles of the audiologist is the initial detection or identification of the existence of a hearing loss (Northern \& Downs, 2002). A number of techniques, including behavioural tests, which require responses from individuals, and objective techniques relying on electrophysiological measurements of the auditory system, have been developed to identify the presence of a hearing loss (Harrell, 2002; Sininger \& Cone-Wesson, 2002). All these techniques however, rely on direct examination of the auditory system by objective measurements or by means of a behavioural response from the patient. Identification of hearing loss by screening other parts of the body for manifestations of a hearing loss has not been reported in the field of audiology to date. Observing signs of hearing loss by such means, have however, been made in the field of iridology.

Iridology is the study of the iris of the eye in order to diagnose medical conditions by analyzing patterns, markings, structures, and irregularities of the pigmentation of the iris (Hauser et al., 2000). The field of iridology is based on the premise that every organ in the body is represented on the surface of the iris of the eye via intricate neural connections (Ernst, 2000). Iridology is practiced by complementary or alternative healthcare practitioners, namely iridologists. According to iridological charts, the zone of the ear is situated between $10 \mathrm{~h} 00$ to $10 \mathrm{~h} 45$ in the right iris and between $1 \mathrm{~h} 45$ to $2 \mathrm{~h} 00$ in the left iris (Hauser et al., 2000). 


\section{Stearn and Swanepoel Afr. J. Trad. CAM (2007) 4 (2): 205 - 210}

Isolated reports in the iridological literature have indicated that pathology of the ear does register as changes in the pigmentation of the iris (Hauser et al., 2000; Kleinstein et al., 1984; Hall, 1980). These include a report that fibers of the iris in the area representative of the ear part, revealing a darker layer of damage in response to loud music over long periods of time in persons suffering from hyperacusis (Hall, 1980). A study investigating iris color and noise induced hearing loss indicated a significant relationship between iris color and high noise exposure in contrast to no significant relationship in cases with low noise exposure (Kleinstein et al., 1984). Other hearing related pathologies, such as Ménière's disease have been reported to register on the iris in the zone representing equilibrium of the ear (Hauser et al., 2000). Ménière's disease is proposed to be caused by an excessive collection of endolymph in the cochlea, and it too, results in a permanent sensorineural hearing loss (Stach, 1998). If these isolated reports indicate that the practice of iridology may contribute to the field of audiology by allowing an alternative method of identifying hearing loss, it is important that this possibility be investigated.

An increasing emphasis on a holistic approach to healthcare is emphasizing such evidencebased inclusion of complementary or alternative medicine into a traditional western model of healthcare. The South African Department of Health has affirmed this move toward holistic healthcare by resolving to ensure that alternative approaches and affordable solutions for dealing with health problems are investigated (Department of Health: Documents, 2004). As the demand for complementary or alternative medicine increases, the need for integration into the national healthcare system also increases. These practices should not however, be integrated into the national healthcare system based merely on public demand, but on the basis of efficacy evidence (Barnes et al., 1999).

Evidence for complementary or alternative approaches to medicine will not only encourage the inclusion thereof in existing healthcare systems but will also increase referrals. A recent study investigating primary healthcare professionals' perceptions on integrating complementary or alternative medicine into primary healthcare indicated that although a high percentage of primary healthcare professionals had previously referred patients for complementary or alternative medical treatments, only $36 \%$ had referred on the basis of evidence that complementary or alternative medicine is helpful (Van Haselen et al., 2004).

The role of iridology as a complementary approach to identify hearing loss is an area of investigation with no research-based reports documenting evidence. This study therefore aimed to explore the efficacy of iridology in identifying the presence of hearing loss.

\section{Materials and Methods}

This exploratory study aimed to determine the efficacy of iridological procedures to identify or screen for sensorineural hearing loss in a selected group of adolescents, by means of iridological procedures. A controlled trial was conducted with an iridologist, blind to the actual hearing status of participants, analyzing the irises of participants with and without hearing loss.

A convenience sample of participants included 50 hearing impaired and 50 normal hearing individuals between the ages of 15 and 19 years. Although participants in this study were adolescents, iridology can be used in the pediatric and adult population as well, although the efficacy of identifying hearing loss by means of iridology has not yet been reported in these age groups. Hearing impaired participants were required to have a moderate to profound bilateral sensorineural hearing loss, which was confirmed from audiologic records conducted in the previous two months. Normal hearing participants were required to undergo an audiological assessment to ensure that their hearing was within normal ranges $(0-15 \mathrm{~dB})$ across the speech frequencies $(500-4000 \mathrm{~Hz})$. Normal middle ear functioning was controlled for by tympanometry for both hearing impaired and normal hearing participants to ensure that middle ear pathology did not influence the results of the iridological analysis. Gender was equally distributed for both the hearing impaired and normal hearing participant groups. The mean age of hearing impaired participants was 16 years, whilst the mean age of normal hearing participants was 17.5 years. One qualified iridologist in full time private practice, with three years of clinical experience, analyzed participants' irises.

Irises were analyzed from photographs of participants' eyes using Jensen's chart of iridology. Analyzing irises of participants from photographs is one of the two commonly used methods in iridology, 
Stearn and Swanepoel Afr. J. Trad. CAM (2007) 4 (2): 205 - 210

the other involving direct observation of the iris through a magnifying glass. Photographs were taken by the researcher after careful instruction by the iridologist using a digital camera with a pixel resolution of 7.2 mega pixels. The photographs were taken in a well lit room, using a light to illuminate the participants' eyes. Both the eyes of each participant were photographed simultaneously. The distance from the participants' eyes from which the photograph was taken was approximately $20 \mathrm{~cm}$. The iridologist received photographs of the irises in digital format to analyze in her practice.

Data collection consisted of two phases, namely a pre-evaluation pilot phase and the actual research phase. The iridologist remained blind with regards to the hearing status of participants. This was achieved by ensuring that the iridologist never met the participants and only analyzed the irises after random numbers were assigned to the photographs. The iridologist was instructed that photos of irises of hearing and hearing impaired participants would be presented at random. Analyses of photographs of irises were done per ear for each subject. The iridologist was asked to provide one of two responses after examination of photographs of a subject's irises, either indicating the presence of a hearing loss or the presence of normal hearing as determined by iridology.

\section{Results}

The categories identified by the iridologist are displayed in figure 1.

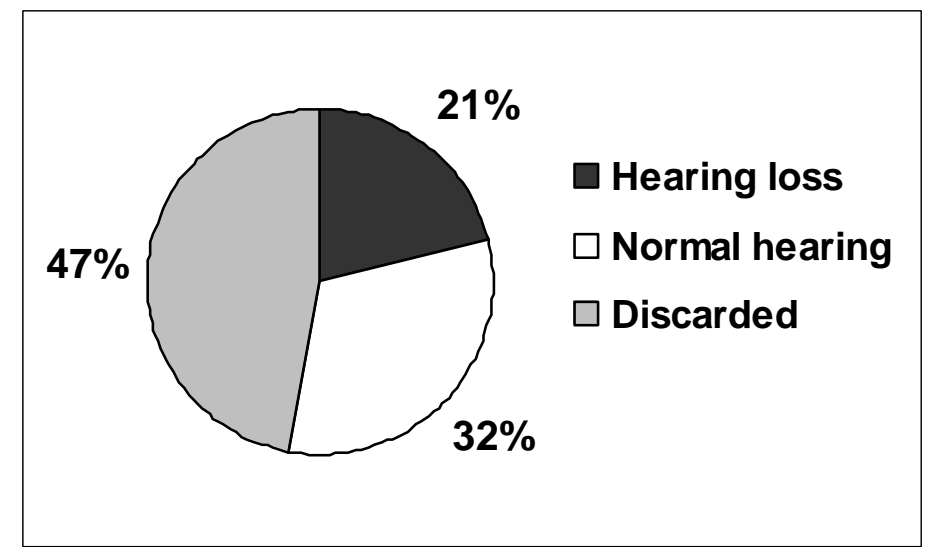

Figure 1: Categories identified by the iridologist in the analysis of subject's irises $(n=100)$

The iridologist discarded 47 photographs due to inadequate picture quality for iridological analysis as judged by the iridologist. This high percentage of photographs that were discarded does not reflect validity of iridological procedures, but rather the validity of procedural aspects of this study. Of the remaining 53 photographs of the sample, the iridologist positively identified $40 \%(n=21 / 53)$ as having a hearing loss, and the remaining $60 \%(n=32 / 53)$ negatively as having normal hearing. The number of correctly identified cases was 37 out of 53 participants (70\%), whilst the number of incorrectly identified cases was 16 out of 53 participants (30\%).

The true and false, positive and negative results of the iridologogical analyses of compared to subject's actual hearing status are represented in Figure 2. False positive identification by means of iridology was double that of false negative results. The overall percentage of false iridological analyses comprised $30 \%(n=16 / 53)$ of all judgments made. The sensitivity, reflecting true positives, of iridological analysis to identify a hearing loss was $59 \%(n=16 / 27)$, whilst the specificity, reflecting the true negatives, was $81 \%(n=21 / 26)$. This indicates that iridological analysis was more efficient in identifying normal hearing than hearing loss.

According to statistical analysis of all 53 cases, using the chi-square test, a significant $(p, 0.05)$ relationship was evident between the iridological result and the actual hearing status of subjects. 
Stearn and Swanepoel Afr. J. Trad. CAM (2007) 4 (2): 205 - 210

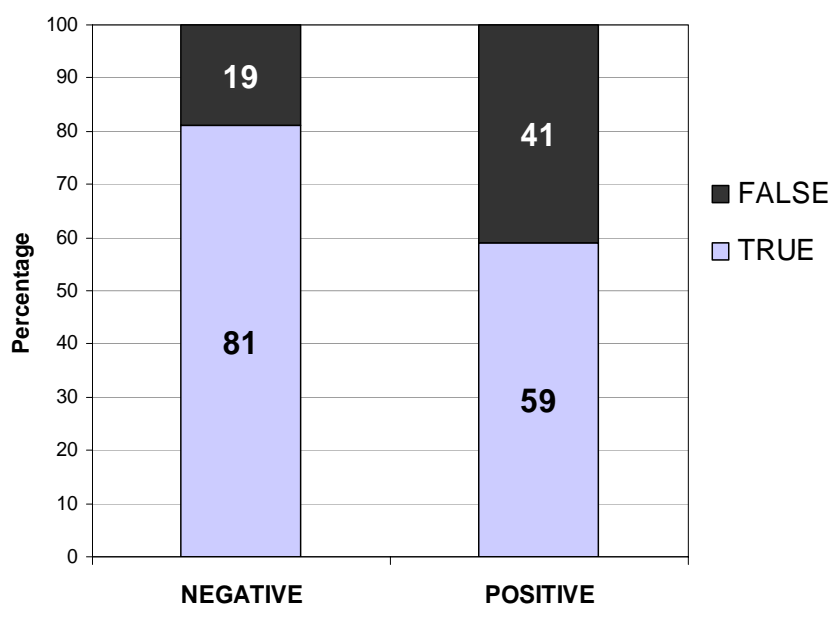

Figure 2: Correct and incorrect identification of hearing status by iridological analysis $(n=53)$

\section{Discussion}

This study indicated a statistically significant relationship between iridological analysis and actual hearing status with better efficacy for correctly identifying normal hearing compared to sensorineural hearing loss, in a group of adolescents. It is important therefore to compare the efficacy of iridology as a screening technique for hearing loss, to existing techniques. The most common audiological screening procedure for subjects who can provide behavioural responses is pure tone audiometry. According to Wallace \& Laurenzo (2005), sensitivity of pure tone audiometric screening is $92 \%$, whilst the specificity is $94 \%$. Screening techniques used for neonates and young infants who cannot provide behavioural responses include Oto-Acoustic Emissions (OAE) and Automated Auditory Brainstem Responses (AABR) (Stach, 1998). According to Watkin (2003), sensitivity and specificity of OAE are $>97.5 \%$ and $94 \%$ respectively. A study conducted by Plinkert et al. (1990) showed OAE sensitivity to be $90 \%$ and specificity to be $91 \%$. The sensitivity of AABR screening in newborns is estimated at or near $100 \%$, whilst the specificity average is approximately $98.5 \%$ according to a Colorado screening program (Mehl \& Thomson, 1998; Mehl \& Thomson, 2002).

The accuracy with which these screening procedures are able to identify cases with normal hearing and hearing loss is significantly higher compared to the results of iridological analyses in the present study. The sensitivity rates of existing screening techniques are as much as $40 \%$ better than those obtained using iridological procedures, whilst the specificity rates are approximately $10-15 \%$ higher than those obtained in this study. Although the efficacy of iridological analyses was statistically significant, it is clear that iridological analyses alone do not provide sensitivity and specificity rates which are comparable to those of existing audiological screening procedures, although a technique like iridology may well be a less expensive.

Possible contributing reasons for poorer sensitivity and specificity rates when using iridological procedures compared to audiological procedures, may be attributed to the following. Whilst audiological screening procedures, such as OAEs or AABRs are objective, iridological analyses are subjective, which may result rely heavily on experience and training. Since this was a pilot study comparisons could not be made between judgments' across iridologists.

Some limitations to the current study are also evident in the limited sample of irises that could be analyzed after 47 photographs were discarded due to poor image quality. In addition to this, according to 
Stearn and Swanepoel Afr. J. Trad. CAM (2007) 4 (2): 205 - 210

some reports, photographic imaging of the eye is inferior to viewing the iris through slit lamp microscopy when doing iridological analyses (Caradonna, 1996). This method of iridological analysis is, however, not universally agreed upon as the most efficient. Certain authors state that photography allows for features in the iris to be enlarged allowing examination of precise detail (Buchanan et al., 1996). Another possible limitation of the current study is the fact that the iris colors were not matched in the hearing impaired and normal hearing participant group. Colors of irises in individuals may vary along a continuum and this needs to be controlled for in order for a true controlled trial to be performed (Buchanan et al., 1996).

The fact that a single iridologist assessed the irises and that only Jensen's chart of iridology was used in the analyses could also be a limitation of the current study. Although this is the most commonly used chart by iridologists (Hall, 1980), there are various other charts of iridology, such as Deck's chart of iridology, that at times indicate differences in mapping (Buchanan et al., 1996). This poses the problem of inter-chart variability, which may result in differences in classification when using different charts. Training in iridological analysis for hearing loss identification by the careful study of hearing impaired individuals' irises may result in improved outcomes and the initial results of this study warrants further investigation.

\section{Conclusion}

This exploratory study revealed some initial promise in screening for hearing loss using iridological procedures with a significant relationship between actual hearing status and iridological analysis. The efficacy of the technique, in terms of sensitivity and specificity, does not however compare favorably to existing audiological hearing screening procedures but initial results warrant further study.

\section{References}

1. Barnes, J, Abbot, N. C., Harkness, E. F. and Ernst, E. (1999). Articles of Complementary Medicine in the Mainstream Medical Literature. Arch Intern Med 15: 1721-1725.

2. Buchanan, T. J., Sutherland, R. J., Terrell, T. J. and Pewsey, A. (1996). An investigation of the relationship between anatomical features in the iris and systemic disease, with reference to iridology. Complement Therapies Med 4: 98-102.

3. Caradonna, B. In Buchanan, T. J., Sutherland, R. J., Terrell, T. J. and Pewsey, A. (1996). An investigation into the relationship between anatomical features in the iris and systematic disease, with reference to iridology. Complement Therapies Med 4: 56-57.

4. Department of Health: Documents (2004). NHIS SA South Africa, viewed 31 August 2004. $<$ http://www.doh.gov.za/docs/sp/2004/sp0611.html>.

5. Ernst, E. (2000). Iridology: not useful and potentially harmful. Arch Opthal 1: 120-121.

6. Hall, D. (1980). Iridology. How The Eyes Reveal Your Health And Your Personality. United States of America: Keats Publishing Inc., 57-198.

7. Harrell, R. W. (2002). Puretone Evaluation. In Katz J. Handbook of Clinical Audiology. $5^{\text {th }}$ Edition. United States of America: Lippincott Williams \& Wilkins, pp. 71.

8. Hauser, H., Karl, J. and Stolz, R. (2000). Information from Structure and Colour. Iridology 1. Heimsheim: Felke Institut, 134-243.

9. Kleinstein, R. N., Seitz, M. R., Barton, T. E. and Smith, C. R. (1984). Iris color and hearing loss. Am J Optom Physiol Opt.61(3):145-149.

10. Mehl, A. and Thomson, V. (1998). Newborn hearing screening: The great omission. Pediatrics 101 (1): $1-6$.

11. Mehl, A and Thomson, V. (2002). The Colorado newborn hearing screening project, 1992-1999: On the threshold of effective population-based universal newborn hearing screening. Pediatrics 109 (1): 1-8.

12. Northern, J. L. and Downs, M. P. (2002). Hearing in Children. $5^{\text {th }}$ Edition. 2002. United States of America: Lippincott Williams \& Wilkins, Philadelphia 159. 
Stearn and Swanepoel Afr. J. Trad. CAM (2007) 4 (2): 205 - 210

13. Plinkert, P. K., Seaterhenn, G., Arold, R. and Zenner, H. P. (1990). Evaluation of otoacoustic emissions in high-risk infants by using an easy and rapid objective auditory screening method. Eur Arch Otorhinolaryngol 247 (6): 356-360.

14. Sininger, Y. S. and Cone-Wesson, B. (2002). Threshold prediction using auditory brainstem response and steady-state evoked potentials with infants and young children. In Katz J. Handbook of Clinical Audiology. $5^{\text {th }}$ Edition. United States of America: Lippincott Williams \& Wilkins, Philadelphia. 298.

15. Stach, B. A.. (1998). Clinical Audiology. An Introduction. United States of America: Delmar Singular Publishing Group Inc., San Diego 135-148.

16. Van Haselen, R. A., Reiber, U., Nickel, I., Jakob, A. and Fisher, P. A. G. (2004). Providing complementary and alternative medicine in primary care: the primary health care workers' perspective. Complement Therapies Med 1: 6-16.

17. Wallace, R. and Laurenzo, J. (2005). Screening for Hearing Impairment: Guide to Clinical Preventive Services. Retrieved August 13, 2005 from the World Wide Web: $<$ http:cpmcnet.columbia.edu/texts/gcps/gcps0045.html>

18. Watkin, P.M. (2003). Neonatal hearing screening - methods and outcome. Audiol Med 1: 165-174. 